\title{
In Vivo Investigation of ALBO-OS Scaffold Based on Hydroxyapatite and PLGA
}

\author{
Vukoman Jokanović, ${ }^{1}$ Božana Čolović, ${ }^{1}$ Dejan Marković, ${ }^{2}$ Milan Petrović, ${ }^{3}$ \\ Milan Jokanović, ${ }^{4}$ Petar Milosavljević, ${ }^{5}$ and Jelena Sopta ${ }^{3}$ \\ ${ }^{1}$ Institute of Nuclear Sciences "Vinča”, University of Belgrade, Mike Petrovića Alasa 12-14, 11001 Belgrade, Serbia \\ ${ }^{2}$ Department of Pediatric and Preventive Dentistry, Faculty of Dentistry, University of Belgrade, Dr. Subotića 8, 11000 Belgrade, Serbia \\ ${ }^{3}$ Clinic for Maxillofacial Surgery, Faculty of Dentistry, University of Belgrade, Dr. Subotića 4, 11000 Belgrade, Serbia \\ ${ }^{4}$ Faculty of Medicine, University of Niš, Bulevar Dr. Zorana Đinđića 81, 18000 Niš, Serbia \\ ${ }^{5}$ Institute for Surgery, Orthopedics and Ophthalmology, Faculty of Veterinary Medicine, University of Belgrade, \\ Bulevar Oslobođenja 18, 11000 Belgrade, Serbia
}

Correspondence should be addressed to Vukoman Jokanović; vukoman@vinca.rs

Received 6 December 2015; Revised 16 March 2016; Accepted 22 March 2016

Academic Editor: Ilaria Armentano

Copyright (C) 2016 Vukoman Jokanović et al. This is an open access article distributed under the Creative Commons Attribution License, which permits unrestricted use, distribution, and reproduction in any medium, provided the original work is properly cited.

\begin{abstract}
A synthetic bone substitute based on calcium hydroxyapatite (CHA) and poly(lactic-co-glycolic) acid (PLGA), described in this paper, was synthesized to fulfill specific requirements like biodegradability, satisfying mechanical properties, optimal porosity and nanotopology, osteoinductive and osteoconductive properties, and so forth. Structural and morphological properties of the new scaffold were analyzed by micro computed tomography and scanning electron microscopy, while its physicochemical properties were investigated by X-ray diffraction and infrared spectroscopy. In vivo biological investigations of the synthesized scaffold were conducted over the cutaneous irritation and biofunctionality assays on rabbits and the test of acute systemic toxicity on mice. The results showed that the scaffold is not irritant and that it does not exhibit any symptoms of acute toxicity. Biofunctionality assays which include evaluation of the presence of various cells of immune response, the presence of neoangiogenesis, percentage of mineralization of newly formed bone, and fibroplasia in the tissue indicated that the new scaffold is suitable for the application in maxillofacial and dental surgery as a bone substitute. Also, it showed significant advantages over commercial product Geistlich Bio-Oss ${ }^{\circledR}$ from the aspect of some parameters of immunological response.
\end{abstract}

\section{Introduction}

Bone tissue engineering techniques have become the main strategy for permanent repair of bone defects, since the use of auto- and allografts is accompanied with the source limitation and immunologic rejection due to their natural origin [1-3]. As many investigations showed, biodegradable porous 3D structures, known as scaffolds, are the most promising solution, because they act as a temporary physical support until their total degradation and replacement by new bone, and, on the other hand, their porosity enables cell growth and facilitates tissue regeneration and vascularization [4-6]. These scaffolds should also be biocompatible, osteoinductive, and osteoconductive, possessing mechanical properties matching those of the tissue they are replacing, and geometrically and functionally designed to mimic the native ECM environment [7-10]. This can be achieved by specific composite scaffold construction, with ceramic part which mimics bone structural hierarchy and thin polymer layer which improves mechanical properties and cell attachment and proliferation. Bearing all that in mind, a composite scaffold of CHA and PLGA, named as ALBO-OS, with very high porosity, was developed as an innovative product. CHA was chosen as one of the most widely used ceramic materials in bone tissue engineering, since it represents the component of natural bone [11]. PLGA, present as a thin coating on the CHA scaffold, is commonly used in tissue engineering due to satisfying mechanical properties, high 
purity, convenient processing, and adjustable degradation rate to match the healing rate of damaged tissue $[12,13]$. The role of the PLGA coating, beside improvement of mechanical properties, is to enhance the scaffold surface for various cell activities, like adhesion, density of their occupation, release of cytoplasmic metabolites, and so forth [14]. Biocompatibility and biofunctionality of so-designed scaffold were evaluated in vivo by the test of acute systemic toxicity performed on mice and the test of cutaneous irritation and biofunctionality assays performed on rabbits. All performed in vivo tests, and particularly the most important assay of biofunctionality, revealed extraordinary results which underline their real potential for clinical application.

\section{Materials and Methods}

2.1. Scaffold Preparation and Characterization. ALBO-OS scaffold was manufactured using the method of polymer foam template. Water suspension of hydrothermally obtained CHA powder, whose synthesis is described in our previous references $[15,16]$, was poured over the polymer foam, with corresponding pore size distribution. The foam was burnt out after which porous scaffold structure was obtained. The system was finally sintered at $1200^{\circ} \mathrm{C}$. The obtained porous CHA compact was further disintegrated into granules of suitable size and PLGA thin film was deposited over them to obtain final product-ALBO-OS scaffold. Details of the scaffold synthesis are given in Appendix A.

Phase analysis of porous CHA was performed by X-ray diffraction (XRD) using a Philips PW 1050 diffractometer with $\mathrm{Cu}-\mathrm{K} \alpha 1-2$ lamp, whereby the data were collected in the $2 \theta$ range from 15 to $65^{\circ}$, in steps of $5^{\circ}$ and exposure time of 2 seconds per step. Phase analysis of ALBO-OS scaffold was performed by Fourier transform infrared spectroscopy (FTIR) using a Nicolet 380 FTIR Spectrometer (Thermo Electron Corporation); infrared spectra were recorded in the spectral range of $4000-400 \mathrm{~cm}^{-1}$.

Microstructure of the scaffold was analyzed by scanning electron microscopy (SEM, JEOL JSM-5300 microscope) and micro computed tomography (CT) (SkyScan, Bruker 1172, Kontich, Belgium). Details of the CT analysis are given in Appendix B.

Nanoporosity of the scaffold was estimated by highpressure mercury intrusion porosimeter (Carlo Erba Porosimeter 2000 with Milestone 100 Software System). The porosimeter operates in the pressure interval $0.1-200 \mathrm{MPa}$, enabling estimation of pores in interval 7.5-15,000 nm.

\subsection{Test of Primary Cutaneous Irritation after ALBO-OS} Application. This study was performed according to modern requirements for animal care: ISO 10993-2:2006 (E) Animal Welfare Requirements.

For the test of primary cutaneous irritation, New Zealand white rabbits were used according to ISO 10993-10:2010 (E) standard. Three animals were used, two males and one female. Their age was 3 months and their body weight was $2.5 \pm$ $0.5 \mathrm{~kg}$. The animals were quarantined three weeks before the start of the experiment. Health status of the animals was checked and only clinically healthy rabbits were taken for the investigations, which have not been previously used in other experiments and with no cutaneous lesions. Twenty-four hours before application of ALBO-OS, rabbits were carefully shaved in the dorsal area, on two lateral sites with the surface of $14 \times 14 \mathrm{~cm}$.

ALBO-OS was applied directly to the shaved skin of each of three rabbits in both lateral cranial fields, making a total of six experimental sites. The size of each test preparation was $2.5 \times 2.5 \mathrm{~cm}$ and was covered with Sensifix patch $(5 \times 5 \mathrm{~cm})$. As a control, 6 areas of the same size $(2.5 \times 2.5 \mathrm{~cm})$ were used, which are located caudal to the experimental sites on the bodies of the same animals. Control surfaces were covered only with Sensifix patches $(5 \times 5 \mathrm{~cm})$. The sample was left in contact with the skin for a period of 4 hours after which it was removed.

The observation of cutaneous lesions was performed 1, 24, 48 , and 72 hours after removal of the preparation. Cutaneous changes on the skin were evaluated for any specified period and marked according to a numerical scale (Table 1).

Irritation score (IS) was obtained by dividing the total sum of the numerical values for erythema and edema for all experimental animals by their number (three). Numerical values obtained for edema and erythema 1 hour after removal of the preparation were neglected. Index of primary cutaneous irritation (PII) was calculated by dividing the IS value by the number of application sites (six). Based on the PII value, the preparation was classified according to the values given in Table 2.

2.3. Test of Acute Systemic Toxicity in Mice after ALBO-OS Application. This study was performed according to modern requirements for animal care: ISO 10993-11:2006 (E), Part 11: Biological Evaluation of Medical Devices.

For the test of acute systemic toxicity, mice (NMRI HAN) were used according to ISO 10993-2:2006 (E) standard. Ten animals were used, six male and four female. Their age was 8 weeks at the beginning of the experiment and 10 weeks at the end of the experiment. Their body weight at the beginning of the experiment was $18-22 \mathrm{~g}$. The animals were placed in the Makrolon cages with a cover of steel wires in groups of three males and two females. The temperature in the room was between 18 and $25^{\circ} \mathrm{C}$, and a relative humidity was between 30 and $70 \%$. The animals had free access to food and water. The health status of the animals during the experiment was monitored daily.

Test preparations were prepared according to the standard ISO 10993-12:2007(E): Sample Preparation and Reference Materials. The mass of $2 \mathrm{~g}$ of ALBO-OS was immersed in $10 \mathrm{~mL}$ of sterilized tap water and thermostated at $37^{\circ} \mathrm{C}$. After 72 hours, the obtained extract was decanted.

The extract was applied once directly into stomach of experimental animals, using gastric probe, in a volume of $1 \mathrm{~mL}$. Five mice ( 3 male and 2 female) were treated with the extract, while the other five served as a control group (they were given $1 \mathrm{~mL}$ of water in the same way). The animals were observed 14 days after the application and signs of toxic reactions were monitored twice a day. After 14 days, all 
TABLE 1: Numerical scale for evaluation of the skin reaction.

\begin{tabular}{ll}
\hline & Degree \\
\hline Erythema & 0 \\
Without erythema & 1 \\
Mild erythema & 2 \\
Well defined erythema & 3 \\
Expressed erythema & 4 \\
Heavy erythema (deep lesions, scabs, burns, and necrosis) & 0 \\
Edema & 1 \\
Without edema & 2 \\
Very mild edema & 3 \\
Mild edema (well defined edges) & 4 \\
Moderate edema ( 1 mm thickness) & 8 \\
Heavy edema (thickness $>1$ mm, spreading out of application site) & \\
Total possible score of irritation & \\
\hline
\end{tabular}

TABLE 2: Index of primary cutaneous irritation.

\begin{tabular}{lc}
\hline PII & Classification of the test preparation \\
\hline $0-0.4$ & Nonirritant \\
$0.5-1.9$ & Mild irritant \\
$2-4.9$ & Irritant \\
$5-8$ & Very irritant \\
\hline
\end{tabular}

animals were sacrificed and pathoanatomic examination was made.

2.4. Biofunctionality Assays. This study was performed on New Zealand white rabbits. Experiments were approved by the Ethics Committee of the Faculty of Dentistry, Belgrade University (number 36/12 from 23.11.2009) and were performed according to ISO 10993-2 Animal Welfare Requirements (modern requirements for animal care). Twenty animals were used in the investigation, ten males and ten females. They were 4 months old at the beginning and 7 months at the end of the experiment. The rabbits' weight was $3.0 \pm 0.5 \mathrm{~kg}$. Their health status was checked daily. The rabbits were kept in standard cages, one animal per cage, placed in a room with temperature of $22 \pm 4^{\circ} \mathrm{C}$ and relative humidity of $55 \pm 10 \%$. They had ad libitum access to standard food for rabbits.

Surgical procedure and implantation details are given in Appendix C. After the assessment period of six, nine, and twelve weeks, the animals were sacrificed and the parietal bones were cut and samples were prepared for the analysis. After assessment period of six and nine weeks, 6 samples with implanted ALBO-OS and 4 samples with implanted Bio-Oss were analyzed. After twelve weeks, a total of 44 samples were analyzed: 20 samples with implanted ALBO-OS, 10 samples left empty as negative controls, and 14 samples with implanted Bio-Oss as positive controls.

2.4.1. Tissue Preparation and Histological Evaluation. Tissue samples of the parietal bone, which corresponded to the full thickness critical sized $(6.0 \mathrm{~mm}$ in diameter) defects, were fixed in $10 \%$ formalin. After decalcification, all samples were embedded in paraffin and serial tissue sections of $5 \mu \mathrm{m}$ thickness were cut (4 per sample). Slides were stained with the Masson's trichrome (MT) stains and observed by optical microscopy (Olympus 5 microscope) using Olympus Cell-B morphometric software. Histopathological parameters were analyzed qualitatively, semiquantitatively, and quantitatively (at magnifications: 40x, 100x, and high power magnification (HPM) of 200x).

The immune response intensity was analyzed over the presence of macrophages, giant cells, lymphocytes, plasma cells, and basophiles, expressed as the number of cells within one microscopic field under HPM (0 cells/HPM, 15 cells/HPM, and 5-10 cells/HPM) and over the presence of neoangiogenesis ( 0 blood vessels/HPM, 1-3 bv/HPM, and 4$7 \mathrm{bv} / \mathrm{HPM})$. The percentage of mineralization $(0,<25 \%, 25-$ $50 \%, 50-75 \%$, and $75-100 \%$ ) of newly formed bone and the presence of connective tissue $(0-25 \%, 26-50 \%$, and $51-100 \%)$ were also examined.

2.4.2. Statistical Analysis. The results are presented as counts (percentages). Chi-square test for trend was used to compare various biofunctionality parameters of ALBO-OS and BioOss. All data analyses were performed with SPSS 20.0 (IBM corp.) statistical package. All $p$ values less than 0.05 were considered significant. Multiple comparisons were done without Bonferroni correction. In all cases, exact tests were used due to small sample sizes.

\section{Results}

3.1. Scaffold Characterization. The phase composition of the $\mathrm{CHA}$, as the main constituent of ALBO-OS, corresponds to calcium hydroxyapatite $\mathrm{Ca}_{10}\left(\mathrm{PO}_{4}\right)_{6}(\mathrm{OH})_{2}$, as confirmed by XRD analysis (Figure 1). Diffraction peaks characteristic for CHA were present at $2 \theta$ values of $25.95,28.20,28.95$, $31.82,32.19,32.84,34.07,39.58,46.54,49.54,53.28$, and $64.02^{\circ}$, with corresponding planes (002), (102), (120), (121), (112), (300), (202), (310), (222), (123), (004), and (304), respectively. 


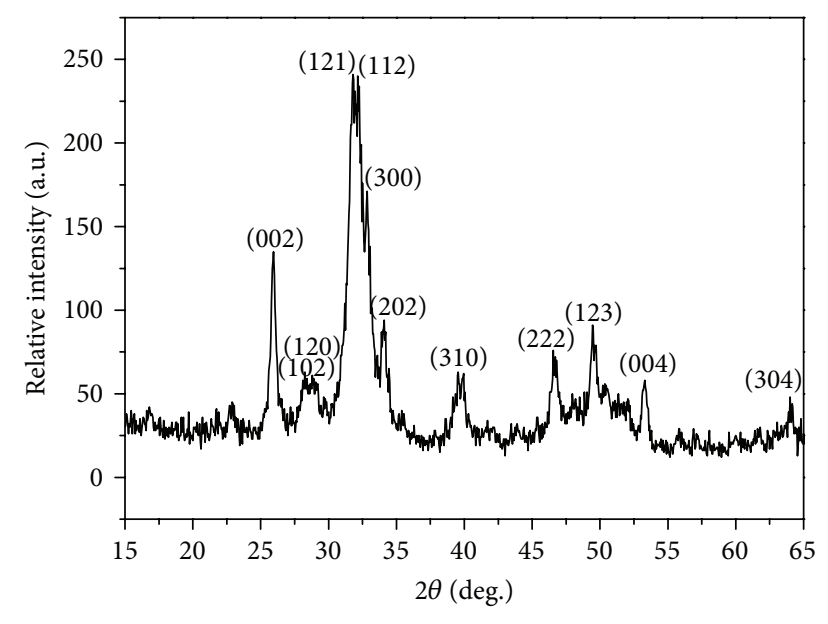

FIGURE 1: XRD pattern of CHA.

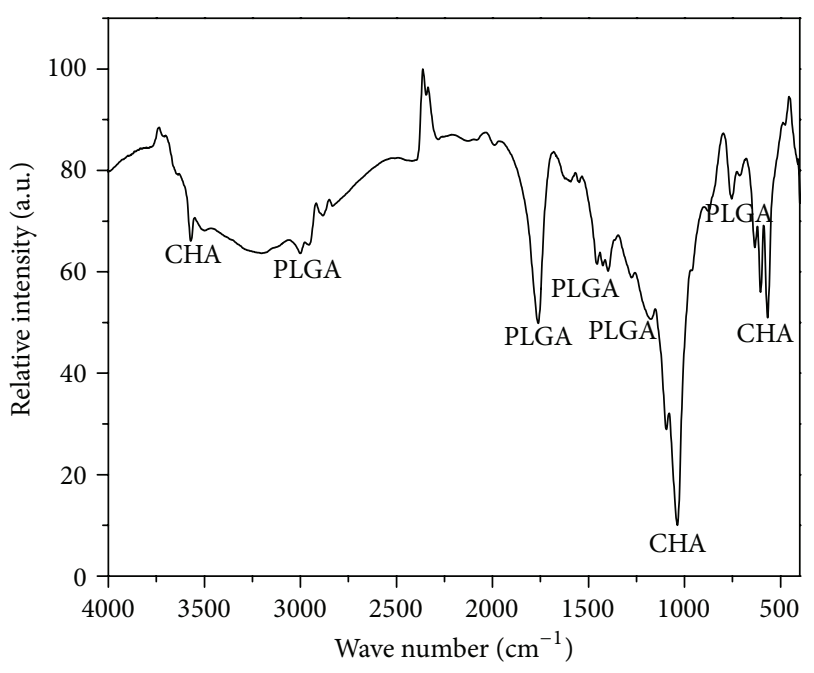

Figure 2: FTIR spectrum of ALBO-OS.

The crystallite size was $15 \mathrm{~nm}$, as calculated using Scherer's equation.

FTIR spectrum of ALBO-OS (Figure 2) showed the bands characteristic for its both components, CHA and PLGA. The bands around $3570,1640,650$, and $600 \mathrm{~cm}^{-1}$ correspond to vibrations of $\mathrm{OH}^{-}$groups in $\mathrm{CHA}$. The bands at 550 to 640 correspond to symmetric stretching of $\mathrm{PO}_{4}{ }^{3}$, while the bands at about 430 to $450 \mathrm{~cm}^{-1}$ correspond partially to the $v_{2}$ symmetric mode of the $\mathrm{PO}_{4}{ }^{3-}$ vibration. The bands corresponding to $\mathrm{CO}_{3}{ }^{2-}$ were found around 1458, 1420, and $870 \mathrm{~cm}^{-1}$, which confirmed that carbonate apatite of type B was obtained, which is very important from the biological standpoint, since type B is the most active form of carbonated apatite prevailing in bones of young people, while the A type is prevailing in bones of elderly people. The bands corresponding to PLGA were found at the following: $2995 \mathrm{~cm}^{-1}$ which can be assigned to the $\mathrm{C}-\mathrm{H}$ asymmetric stretching vibration; around 2950 and $2880 \mathrm{~cm}^{-1}$ corresponding to the $\mathrm{C}-\mathrm{H}$ symmetric stretch; $1760 \mathrm{~cm}^{-1}$ corresponding to the $\mathrm{C}=\mathrm{O}$
TABLE 3: Pore size distribution.

\begin{tabular}{lc}
\hline Pore diameter, $\mu \mathrm{m}$ & $\begin{array}{c}\text { Volume partition in the total pore } \\
\text { volume, } \%\end{array}$ \\
\hline 2.23 & $6-90$ \\
2.76 & $90-150$ \\
3.26 & $150-210$ \\
6.13 & $210-294$ \\
11.13 & $294-390$ \\
21.06 & $390-498$ \\
19.1 & $498-594$ \\
18.38 & $594-690$ \\
15.95 & $690-774$ \\
\hline
\end{tabular}

stretch; about $1100-1280 \mathrm{~cm}^{-1}$ corresponding to the aliphatic ether C-O-C stretch; $1400-1500 \mathrm{~cm}^{-1}$ corresponding to $\mathrm{CH}_{2}$, $\mathrm{CH}_{3}$, and $\mathrm{CH}$ deformation vibrations; and around $750 \mathrm{~cm}^{-1}$ which can be attributed to the rocking motion of long $\mathrm{CH}_{2}$ chain.

A very high porosity of the CHA scaffold, as the main constituent of ALBO-OS, can be seen in micro CT image (Figure 3(a)). CTAn 1.14.4.1 software enabled detailed analysis of porosity parameters, showing that open and total porosity are equal (75.4\%), volume partition of closed pores is negligible, and the number of connected pores per $\mathrm{mm}^{3}$ is very high (13.6). The value of the structure model index parameter (1.1) indicated cylindrical shape of the pores. CT also gave the information about pore size and pore size distribution (Table 3).

SEM analysis enabled deeper insight into the structure of CHA granules (Figure 3(b)) showing a very developed scaffold internal geometry with particles of cylindrical shape. Particle length is in the range $300-900 \mathrm{~nm}$ and the width is between 180 and $250 \mathrm{~nm}$. Pores between the particles range from 90 to $300 \mathrm{~nm}$.

The nanostructure of the scaffold walls was additionally investigated by mercury porosimetry which showed the presence of nanopores in the diameter range $30-400 \mathrm{~nm}$, with prevailing pores in the range $100-200 \mathrm{~nm}$.

3.2. Results of the Cutaneous Irritation Test. Results of the test of cutaneous irritation after application of ALBO-OS on the skin of New Zealand white rabbits are shown in Table 4. As it can be seen, ALBO-OS showed no irritating effects, since all values for erythema and edema were zero. The same values were obtained for control sites.

3.3. Results of the Acute Systemic Toxicity Test. Treated animals did not exhibit signs of toxic reactions immediately after application as well as later in the observations. They behaved normally, in line with expectations for their species, sex, age, and environment. The reaction of the animals to the provoked behavior was normal and expected. There were no signs of neurological dysfunction. Motor activity and muscle tonus were regular as well as respiration and heart rhythm. Hygienic behavior of animals was normal. The eyes 


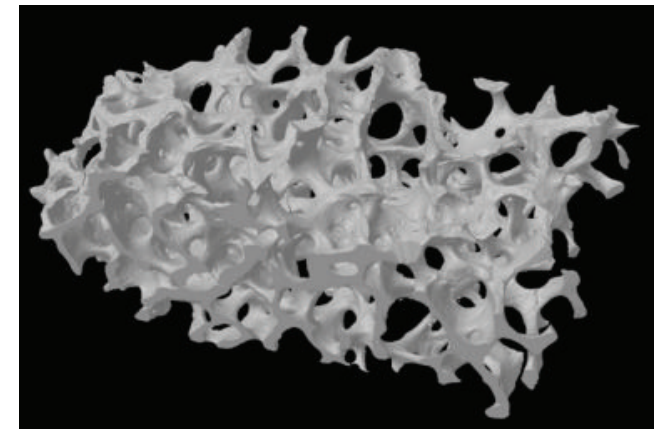

(a)

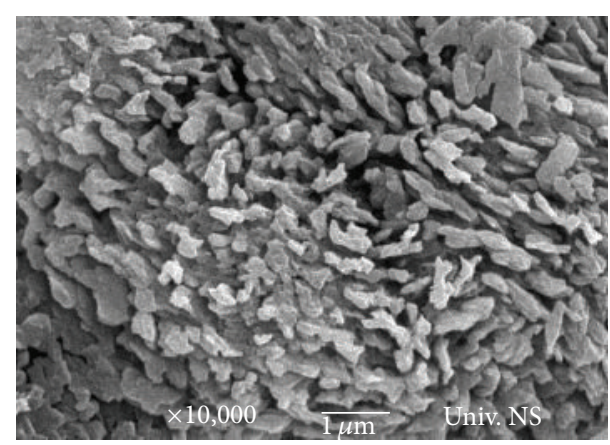

(b)

FIGURE 3: (a) CT image and (b) SEM micrograph of ALBO-OS.

TABLE 4: Evaluation of the irritation degree of ALBO-OS.

\begin{tabular}{|c|c|c|c|c|c|c|c|c|c|c|c|c|c|}
\hline \multirow{3}{*}{ Rabbit } & \multicolumn{4}{|c|}{$24 \mathrm{~h}$} & \multicolumn{4}{|c|}{$48 \mathrm{~h}$} & \multicolumn{4}{|c|}{$72 \mathrm{~h}$} & \multirow{3}{*}{ PII } \\
\hline & \multicolumn{2}{|c|}{ Erythema } & \multicolumn{2}{|c|}{ Edema } & \multicolumn{2}{|c|}{ Erythema } & \multicolumn{2}{|c|}{ Edema } & \multicolumn{2}{|c|}{ Erythema } & \multicolumn{2}{|c|}{ Edema } & \\
\hline & $\mathrm{L}$ & $\mathrm{D}$ & $\mathrm{L}$ & $\mathrm{D}$ & $\mathrm{L}$ & $\mathrm{D}$ & $\mathrm{L}$ & $\mathrm{D}$ & $\mathrm{L}$ & $\mathrm{D}$ & $\mathrm{L}$ & $\mathrm{D}$ & \\
\hline 1 & 0 & 0 & 0 & 0 & 0 & 0 & 0 & 0 & 0 & 0 & 0 & 0 & \\
\hline 2 & 0 & 0 & 0 & 0 & 0 & 0 & 0 & 0 & 0 & 0 & 0 & 0 & 0,00 \\
\hline 3 & 0 & 0 & 0 & 0 & 0 & 0 & 0 & 0 & 0 & 0 & 0 & 0 & \\
\hline
\end{tabular}

L: left application site on the rabbit's back.

D: right application site on the rabbit's back.

were clear and clean, and nasal openings and other natural openings were clean. No changes on the skin were observed. Experimental animals did not show eating disorders; they ate and drank water in the usual way. Consumption of food and water for the experimental and control animals was not significantly different. There was no significant variation in body weight gain of experimental compared to control animals. During the experimental period, there was no death of the experimental animals. Postmortem macroscopic examination of organs and tissues did not show changes in any animal, from both the treated and the control group.

3.4. Results of the Biofunctionality Assays. Preliminary analysis of the tissue samples was performed 6 and 9 weeks after implantation of ALBO-OS and Bio-Oss (Figures 4 and 5). Six defects filled with ALBO-OS and four defects filled with Bio-Oss were analyzed. Although the cells of immune response were counted for each sample, statistical analysis was not performed due to insufficient number of samples. However, the number of samples was enough to estimate the degree of immune response of both materials. After 6 weeks, particles of both materials are visible (Figure 4). Fibrovascular proliferation with many blood vessels and woven bone production can be observed which indicates that the process of new bone formation is in an initial phase for both materials. The data obtained after 9 weeks showed significantly milder immune response in defects filled with ALBO-OS than in those with Bio-Oss since much larger number of giant cells in the defects with Bio-Oss was observed (Figure 5). Comparative morphometric analysis of the defects showed larger fields of mineralization in ALBOOS $(181 \mu \mathrm{m})$ than in Bio-Oss $(96 \mu \mathrm{m})$ and proportionately more pronounced fibrous proliferation in Bio-Oss $(86 \mu \mathrm{m})$ than in ALBO-OS $(180 \mu \mathrm{m})$.

The tissue preparations obtained 12 weeks after implantation of test materials (ALBO-OS, Bio-Oss, and empty defects) were analyzed for the presence of cells of immune response: macrophages, giant cells, lymphocytes, plasma cells, and basophiles. A total of 44 samples were analyzed: 20 with ALBO-OS, 14 with Bio-Oss, and 10 without implanted materials. Results were expressed as a percentage of defects filled with ALBO-OS/Bio-Oss or empty defects in which the cells of immune response were present in certain number (Table 5).

Morphometric analysis revealed that in $70-75 \%$ of defects filled with ALBO-OS there were no cells of immune response, 1-5 cells/HPM were present in $25-30 \%$ of defects, and more than 5 cells/HPM were not observed in any defect. As it can be seen in Table 1, in defects filled with BioOss, macrophages and giant cells were present in $80-85 \%$ of defects, showing significantly stronger immune response than ALBO-OS. The difference in presence of the other cells (lymphocytes, plasma cells, and basophils) is less expressed. This was confirmed by post hoc testing which indicated the significant differences between Bio-Oss and ALBO-OS: $p=$ 0.002 in the case of macrophages and $p<0.001$ in the case of giant cells (statistical differences between ALBO-OS/Bio-Oss and empty defects are given and discussed in Appendix D).

Neoangiogenesis expressed over the number of blood vessels showed similar behavior for ALBO-OS and Bio-Oss, while the percentages of mineralization and connective tissue 
TABLE 5: Immunological response 12 weeks after implantation of ALBO-OS and Bio-Oss.

\begin{tabular}{|c|c|c|c|c|c|}
\hline \multirow{2}{*}{ Immune cells } & \multirow{2}{*}{ Number of cells per HPM } & \multicolumn{3}{|c|}{ Percentage of defects } & \multirow{2}{*}{$\begin{array}{c}p \text { value } \\
\text { ALBO-OS/Bio-Oss }\end{array}$} \\
\hline & & ALBO-OS & Bio-Oss & Empty defect & \\
\hline \multirow{3}{*}{ Macrophages } & No & 70 & 21.4 & 0 & \multirow{3}{*}{0.002} \\
\hline & $1-5$ & 30 & 50 & 20 & \\
\hline & $5-10$ & 0 & 28.6 & 80 & \\
\hline \multirow{3}{*}{ Giant cells } & No & 70 & 14.3 & 10 & \multirow{3}{*}{$<0.001$} \\
\hline & $1-5$ & 30 & 57.1 & 20 & \\
\hline & $5-10$ & 0 & 28.6 & 70 & \\
\hline \multirow{3}{*}{ Lymphocytes } & No & 75 & 64.3 & 40 & \multirow{3}{*}{0.257} \\
\hline & $1-5$ & 25 & 21.4 & 60 & \\
\hline & $5-10$ & 0 & 14.3 & 0 & \\
\hline \multirow{3}{*}{ Plasma cells } & No & 75 & 71.4 & 40 & \multirow{3}{*}{0.746} \\
\hline & $1-5$ & 25 & 21.4 & 60 & \\
\hline & $5-10$ & 0 & 7.1 & 0 & \\
\hline \multirow{3}{*}{ Basophils } & No & 75 & 71.4 & 50 & \multirow{3}{*}{0.562} \\
\hline & $1-5$ & 25 & 14.3 & 50 & \\
\hline & $5-10$ & 0 & 14.3 & 0 & \\
\hline
\end{tabular}

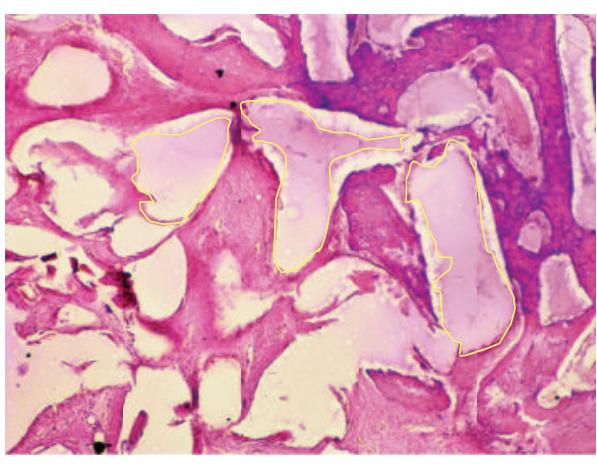

(a)

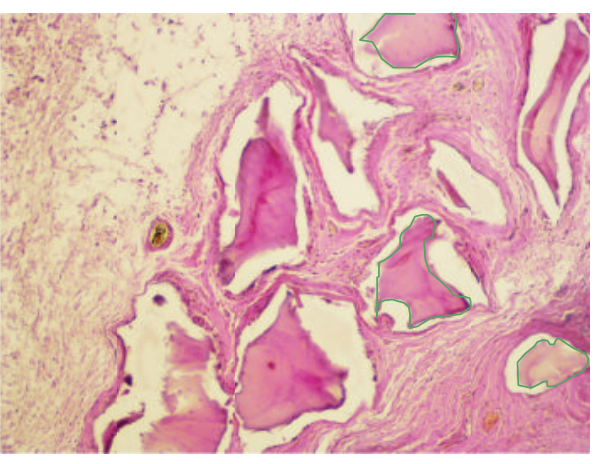

(b)

Figure 4: Comparative review of defects 6 weeks after implantation, for (a) ALBO-OS and (b) Bio-Oss. Particles of material ALBO-OS (encircled in yellow) and Bio-Oss (encircled in green) surrounded by tissue response on material's presence. Note new forming fibrovascular proliferation with many blood vessels and woven bone production (HE stain, magnification 100x).

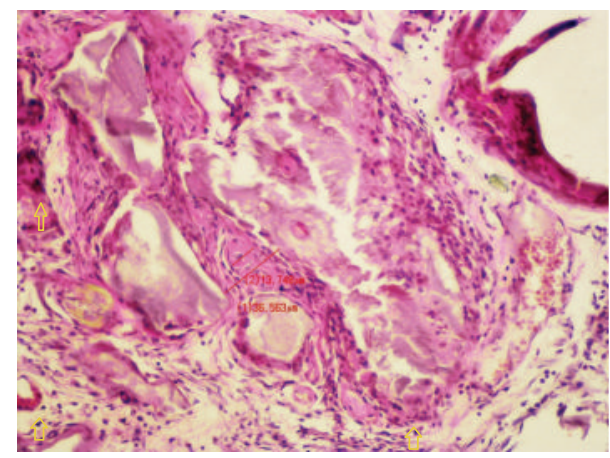

(a)

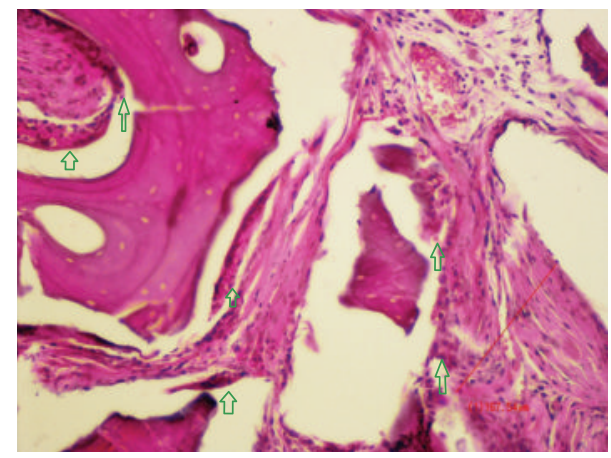

(b)

FIGURE 5: Comparative review of defects 9 weeks after implantation for (a) ALBO-OS and (b) Bio-Oss. Particles of material ALBO-OS (yellow arrow) and Bio-Oss (green arrow) surrounded by fibroblasts and many multinuclear foreign body giant cells. A significantly larger number of giant cells around the Bio-Oss particles were observed (HE stain, magnification 100x). 
TABLE 6: Presence of neoangiogenesis, mineralization, and connective tissue in defects 12 weeks after implantation of ALBO-OS and Bio-Oss.

\begin{tabular}{|c|c|c|c|c|c|}
\hline \multirow{2}{*}{ Parameter } & \multirow{2}{*}{ Response } & \multicolumn{3}{|c|}{ Percentage of defects } & \multirow{2}{*}{$\begin{array}{c}p \text { value } \\
\text { ALBO-OS/Bio-Oss }\end{array}$} \\
\hline & & ALBO-OS & Bio-Oss & Without & \\
\hline \multirow{3}{*}{ Neoangiogenesis } & No & 55 & 57.1 & - & \multirow{3}{*}{1.000} \\
\hline & 1-3 bv/HPM & 35 & 28.6 & - & \\
\hline & 4-7 bv/HPM & 10 & 14.3 & - & \\
\hline \multirow{5}{*}{ Mineralization } & No & 0 & 0 & 20 & \multirow{5}{*}{$<0.001$} \\
\hline & $<25 \%$ & 0 & 28.6 & 60 & \\
\hline & $25-50 \%$ & 0 & 57.1 & 20 & \\
\hline & $51-75 \%$ & 30 & 14.3 & 0 & \\
\hline & $76-100 \%$ & 70 & 0 & 0 & \\
\hline \multirow{4}{*}{ Connective tissue } & No & 75 & 0 & 0 & \multirow{4}{*}{$<0.001$} \\
\hline & $0-25 \%$ & 25 & 14.3 & 0 & \\
\hline & $26-50 \%$ & 0 & 28.6 & 30 & \\
\hline & $51-100 \%$ & 0 & 57.1 & 70 & \\
\hline
\end{tabular}

were significantly different in these groups (Table 6). Significantly higher mineralization is observed in defects filled with ALBO-OS, in comparison to Bio-Oss. The connective tissue was not observed in even $75 \%$ defects filled with ALBO-OS, while in the case of Bio-Oss connective tissue was present in high percentage in the largest number of defects (57.1\%). Post hoc testing regarding mineralization and connective tissue showed significant differences between Bio-Oss and ALBOOS $(p<0.001)$.

The newly formed bone at the site of ALBO-OS implantation showed the regular structure of the bone beds (Figure 6(a)). The presence of mineralized osteoid was dominant. Bone tissue showed lamellar structure. At the site of BioOss implantation, beds of new bone were filling the defect in an irregular schedule (Figure 6(b)). The beds contained approximately the same amount of unmineralized and mineralized osteoid. The particulates of unchanged material can be observed in Figure 6(b). All this suggests that the process of maturation of newly formed bone in the case of ALBO-OS is in the final stage, unlike the case of Bio-Oss where the bone is in an early phase of formation.

\section{Conclusions}

The synthesized bone scaffold based on CHA and PLGA showed a very high porosity and nanotopology suitable for cell adhesion and proliferation.

The results of the test of cutaneous irritation after application of ALBO-OS on rabbits' skin showed that ALBOOS is not irritant, while the results of the test of acute systemic toxicity showed that ALBO-OS does not exhibit any symptoms of toxicity in mice, according to the standard ISO 10993.

Biofunctionality tests performed six weeks after implantation of ALBO-OS and Bio-Oss showed the presence of particles of both materials, pronounced fibrovascular proliferation with many blood vessels and new bone production in an initial phase. Tests performed after nine weeks showed certain advantages of ALBO-OS, expressed as lower number of immune cells and higher degree of mineralization.
Tests performed after twelve weeks showed that the immune response, expressed over the number of macrophages and giant cells, in the defects with ALBO-OS was statistically lower than in defects with Bio-Oss. Significantly higher degree of mineralization and lower degree of connective tissue in defects with ALBO-OS in comparison to those with Bio-Oss indicate clearly that the formation of a new bone is in its final stage for ALBO-OS, while for Bio-Oss it is in an early stage. Lamellar structure of a new bone typical for mature bone also confirmed that the osteointegration is almost completed in defects filled with ALBO-OS.

All these indicate that ALBO-OS can be successfully applied as a bone substitute in dental and maxillofacial surgery.

\section{Appendix}

\section{A. Scaffold Synthesis}

The synthesis of the scaffold, called ALBO-OS, consisted of three stages. The first one was the hydrothermal synthesis of HA powder from an approximately stoichiometric mixture of $\left(\mathrm{NH}_{4}\right)_{2} \mathrm{HPO}_{4}$ and $\mathrm{Ca}(\mathrm{OH})_{2}$ [15]. Briefly, $500 \mathrm{~mL}$ of $2.32 \mathrm{cmol}$ aqueous solution of $\left(\mathrm{NH}_{4}\right)_{2} \mathrm{HPO}_{4}$ was poured into $500 \mathrm{~mL}$ of $3.02 \mathrm{cmol}$ aqueous solution of $\mathrm{Ca}(\mathrm{OH})_{2}$, under vigorous stirring. The mixture $\mathrm{pH}$ was adjusted to 7.4 , and then it was autoclaved at $150^{\circ} \mathrm{C}$ under a pressure of $5 \cdot 10^{5} \mathrm{~Pa}$ for $8 \mathrm{~h}$. After the hydrothermal treatment, the precipitate was decanted, dried at $80^{\circ} \mathrm{C}$ for $48 \mathrm{~h}$, washed with deionized water, and centrifuged. In the next step, $5 \mathrm{~g}$ of hydrothermally synthesized HA and $1.5 \mathrm{~g}$ of poly(ethylene vinyl acetate)/poly(ethylene vinyl versatate) (PEVA/PEVV) were mixed and further processed in the autoclave at $120^{\circ} \mathrm{C}$ for $2 \mathrm{~h}$.

The obtained HA powder was ultimately used for the production of HA granules. First, it was mixed with water to form ceramic slurry. To enhance the wettability of the slurry and its rheological properties, $2 \%$ of PVA was added. Polyurethane (PU) foams with required pore size distribution were then dipped into the slurry and gently squeezed several 


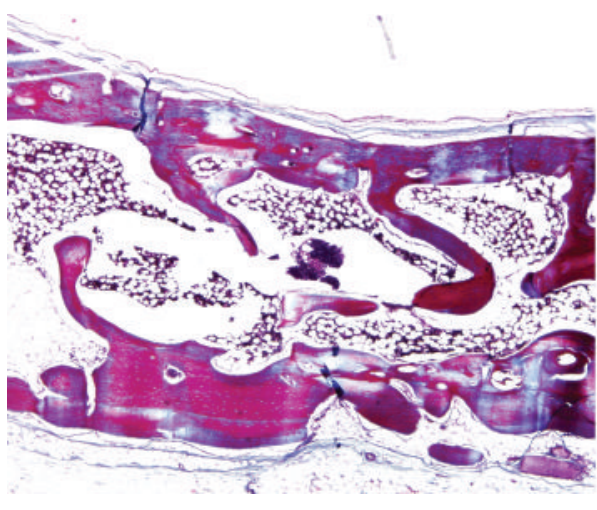

(a)

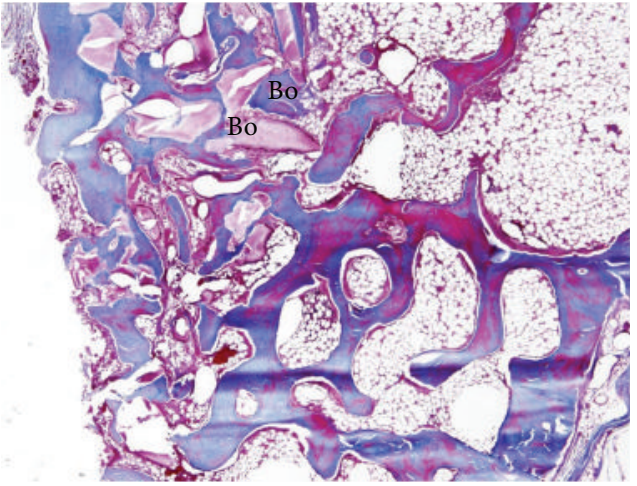

(b)

FIGURE 6: A typical appearance of newly formed bone 12 weeks after implantation: (a) ALBO-OS: regular structure of bone beds in new bone; dominant presence of mineralized osteoid; lamellar structure of bone tissue; (b) Bio-Oss: newly formed bone beds which are of irregular structure; amounts of mineralized and unmineralized osteoid which are approximately the same; material particulates which are visible (Masson's trichrome stain, magnification 40x).

times to allow the slurry to penetrate the foams and the excess slurry to be squeezed out. Compressed air through an air gun was used to avoid the blockage of pores. The ceramic slurry coated PU foams were left to dry at room temperature, then heated in an oven at $600^{\circ} \mathrm{C}$ to burn away the foam, and finally sintered at $1200^{\circ} \mathrm{C}$ for $4 \mathrm{~h}$. The obtained porous HA compact was further disintegrated into granules of sizes $300 \mu \mathrm{m}-1 \mathrm{~mm}$.

The final step in ALBO-OS synthesis was the deposition of a thin film of PLGA onto the surface of HA granules. PLGA pellets (Durect Corporation, 50:50, $M=45000-70000$ ) were dissolved in chloroform to obtain a $1 \% \mathrm{w} / \mathrm{w}$ solution, which was then poured over the HA granules. After the solvent evaporation, thin PLGA film was formed on the granule surfaces.

\section{B. Micro Computed Tomography}

Scaffold specimen was scanned using micro computed tomography (CT) (SkyScan, Bruker 1172, Kontich, Belgium) with a source voltage of $100 \mathrm{kV}$, a current of $100 \mu \mathrm{A}$, exposure time of $1000 \mathrm{~ms}$, and copper aluminium filter. The specimen was attached to a stage that rotated $180^{\circ}$ with images acquired every $0.4^{\circ}$. The slice thickness was $5 \mu \mathrm{m}$ isotropic resolution and 2,048 $\times 2,048$ pixels per slice. Cross-sectional slices were reconstructed using the NRecon v.1.6.9.8 software with beam hardening correction of $10 \%$, ring artifact correction of $9 \%$, postalignment of -2.5 , and smoothing of 2 . For porosity assessment, CTAn 1.14.4.1 software (SkyScan, Bruker) was used for all analyses. CTAn 1.14.4.1 software (SkyScan, Bruker) with threshold set to 66-256 values was employed to distinguish scaffold and air allowing determination of following structural morphometric parameters: total and open porosity (\%), average pore size and pore size distribution $(\mu \mathrm{m})$, structure model index, and connectivity density $\left(1 / \mathrm{mm}^{3}\right)$.

\section{Surgical Procedure}

Dissociative anesthesia was conducted in all surgical procedures. The animals were premedicated by intramuscular administration of Xylazine (2\% Xylazine, $5 \mathrm{mg} / \mathrm{kg}$ body weight, Cp Pharma, Bergdorf, Germany), followed by intramuscular administration of Ketamine (Ketamine $500 \mathrm{mg} /$ $\mathrm{mL}, 35 \mathrm{mg} / \mathrm{kg}$ body weight, Laboratorio Sanderson SA, Santiago, Chile) and Acepromazine (Acepromazine $50 \mathrm{~mL}$, $0.75 \mathrm{mg} / \mathrm{kg}$ body weight, Boehringer Ingelheim Vetmedica, Inc., St. Joseph, MO 64506, USA).

The surgical procedure was performed under aseptic conditions in a manner that ensures minimal trauma. The scalp of rabbits was shaved and disinfected with iodine solution, and then an incision in the middle skull base was performed. The central incision on the rabbit head stretched from the parietal (os parietale, sutura coronalis) to the frontal bone (os frontale, incisura supraorbitalis caudalis). Musculus frontalis and musculus frontoscutularis were cut to the parietal and frontal bones. Skin and periosteum were carefully cut and withdrawn to reveal parietal bones. On both sides of calvaria, two full thickness critical sized $(6.0 \mathrm{~mm}$ in diameter) defects were made using a trepan borer (AC Dental Implant System, trepan borer $6.0 \mathrm{~mm}$, total length $32 \mathrm{~mm}$, blade length $15.8 \mathrm{~mm}$, inner diameter $6 \mathrm{~mm}$, outer diameter $6.95 \mathrm{~mm}$, titanium alloy), with a continuous flushing with saline solution (Natrii Chloridi Infundibile, solution for infusion, Zdravlje AD Leskovac, Serbia).

The bone tissue was removed with a sharp excavator. Randomization of the tested materials was carried out by the materials distribution using rotational technique (in a clockwise direction, in accordance with the modified Latin square design) to ensure a balanced distribution of the materials between the front and rear regions of the calvaria bone. The skin is then returned to its place to cover the experimental area and was stitched up with sutures (4-0 Sofsilk ${ }^{\mathrm{TM}}$, Syneture ${ }^{\circledR}$, England) applying horizontal mattress sutures. 
TABLE 7: Statistical $p$ values for the presence of various immune cells in defects filled with ALBO-OS or Bio-Oss and empty critical defects.

\begin{tabular}{llccc}
\hline & & & \\
& & ALBO-OS & \\
& & B values & $<0.001$ & $<$ Overall \\
\hline & Macrophages & 0.016 & $<0.001$ & $<0.001$ \\
Empty defects & Giant cells & 0.146 & 0.108 & 0.001 \\
& Lymphocytes & 0.762 & 0.108 & 0.105 \\
& Plasma cells & 0.487 & 0.231 & 0.253 \\
\hline
\end{tabular}

TABLE 8: Statistical $p$ values for the presence of mineralization and connective tissue in defects filled with ALBO-OS or Bio-Oss and empty critical defects.

\begin{tabular}{llccc}
\hline & & & \\
& & ALBO-OS & Overall \\
\hline \multirow{2}{*}{ Empty defects } & Mineralization & Bio-Oss & $<0.001$ & $<0.001$ \\
& Connective tissue & 0.012 & $<0.001$ & $<0.001$ \\
\hline
\end{tabular}

Postoperatively, the animals were injected subcutaneously with analgesics (Moradol, Galenika, Serbia) at a dose of 0.1 to $2.0 \mathrm{mg} / \mathrm{kg}$ of body weight every 8 hours for three days. Antibiotic (Chloramphenicol, Galenika, Serbia) at a dose of $60 \mathrm{mg} / \mathrm{kg}$ of body weight was administered once daily for five days. The animals were placed in individual cages until the end of the experiment. All animals recovered well after the surgical procedures without any signs of infection, and skin wounds healed per primam intentionem.

After an assessment period of 12 weeks, the animals were sacrificed with intravenous injection of $10 \mathrm{~mL}$ Pentobarbital (Sigma-Aldrich, Germany). After that, the parietal bones were cut out and immersed in $10 \%$ formalin.

\section{Statistical Analysis}

Based on the results of statistical analysis, it was showed that there are statistically significant differences between groups of macrophages and giant cell (Table 7). When it comes to macrophages, subsequent testing between groups determined that there is a statistically significant difference between empty defects and Bio-Oss $(p=0.016)$ and empty defects and ALBO-OS $(p<0.001)$. The same analysis shows that when it comes to giant cell, there is no significant difference between empty defects and Bio-Oss ( $p=0.146)$, but there is a significant difference between empty defects and ALBO-OS $(p<0.001)$.

Table 8 clearly shows that the difference between groups mineralization and connective tissue is significant. By subsequent testing between groups of mineralization, it was established that the difference is significant between the empty defects and Bio-Oss $(p=0.012)$ and between the empty defects and ALBO-OS $(p<0.001)$. For connective tissue (fibroplasia), the differences were not significant between the empty defects and Bio-Oss $(p=0.370)$, while the differences were significant between the empty defects and ALBO-OS $(p<0.001)$.

\section{Competing Interests}

The authors declare that they have no competing interests.

\section{Acknowledgments}

This study was supported by the Ministry of Education, Science and Technological Development of the Republic of Serbia (Project no. 172026).

\section{References}

[1] A. Bigham-Sadegh, I. Karimi, M. Shadkhast, and M.-H. Mahdavi, "Hydroxyapatite and demineralized calf fetal growth plate effects on bone healing in rabbit model," Journal of Orthopaedics and Traumatology, vol. 16, no. 2, pp. 141-149, 2015.

[2] D. F. Williams, "On the mechanisms of biocompatibility," Biomaterials, vol. 29, no. 20, pp. 2941-2953, 2008.

[3] J. J. Li, D. L. Kaplan, and H. Zreiqat, "Scaffold-based regeneration of skeletal tissues to meet clinical challenges," Journal of Materials Chemistry B, vol. 2, no. 42, pp. 7272-7306, 2014.

[4] X. Wang, Y. Wang, L. Li, Z. Gu, H. Xie, and X. Yu, "Stimulations of strontium-doped calcium polyphosphate for bone tissue engineering to protein secretion and mRNA expression of the angiogenic growth factors from endothelial cells in vitro," Ceramics International, vol. 40, no. 5, pp. 6999-7005, 2014.

[5] J.-Y. Baek, Z.-C. Xing, G. Kwak et al., "Fabrication and characterization of collagen-immobilized porous $\mathrm{PHBV} / \mathrm{HA}$ nanocomposite scaffolds for bone tissue engineering," Journal of Nanomaterials, vol. 2012, Article ID 171804, 11 pages, 2012.

[6] D. W. Hutmacher, "Scaffolds in tissue engineering bone and cartilage," Biomaterials, vol. 21, no. 24, pp. 2529-2543, 2000.

[7] D. W. Hutmacher, J. T. Schantz, C. X. F. Lam, K. C. Tan, and T. C. Lim, "State of the art and future directions of scaffold-based bone engineering from a biomaterials perspective," Journal of Tissue Engineering and Regenerative Medicine, vol. 1, no. 4, pp. 245-260, 2007.

[8] T. Douglas, E. Pamula, D. Hauk et al., "Porous polymer/hydroxyapatite scaffolds: characterization and biocompatibility investigations," Journal of Materials Science: Materials in Medicine, vol. 20, no. 9, pp. 1909-1915, 2009.

[9] S. C. Rizzi, D. J. Heath, A. G. A. Coombes, N. Bock, M. Textor, and S. Downes, "Biodegradable polymer/hydroxyapatite composites: surface analysis and initial attachment of human osteoblasts," Journal of Biomedical Materials Research, vol. 55, no. 4, pp. 475-486, 2001. 
[10] Y. Zhou, F. Chen, S. T. Ho, M. A. Woodruff, T. M. Lim, and D. W. Hutmacher, "Combined marrow stromal cell-sheet techniques and high-strength biodegradable composite scaffolds for engineered functional bone grafts," Biomaterials, vol. 28, no. 5, pp. 814-824, 2007.

[11] H. Aoki, Science and Medical Applications of Hydroxyapatite, Japan Association of Apatite Science, Takayama Press System Center Co., Tokyo, Japan, 1991.

[12] C. M. Agrawal and R. B. Ray, "Biodegradable polymeric scaffolds for musculoskeletal tissue engineering," Journal of Biomedical Materials Research, vol. 55, no. 2, pp. 141-150, 2001.

[13] M. Ngiam, S. Liao, A. J. Patil, Z. Cheng, C. K. Chan, and S. Ramakrishna, "The fabrication of nano-hydroxyapatite on PLGA and PLGA/collagen nanofibrous composite scaffolds and their effects in osteoblastic behavior for bone tissue engineering," Bone, vol. 45, no. 1, pp. 4-16, 2009.

[14] M. Thomas, A. Arora, and D. S. Katti, "Surface hydrophilicity of PLGA fibers governs in vitro mineralization and osteogenic differentiation," Materials Science and Engineering C, vol. 45, pp. 320-332, 2014.

[15] V. Jokanović, D. Izvonar, M. D. Dramićanin et al., "Hydrothermal synthesis and nanostructure of carbonated calcium hydroxyapatite," Journal of Materials Science: Materials in Medicine, vol. 17, no. 6, pp. 539-546, 2006.

[16] V. Jokanović, B. Jokanović, D. Marković et al., "Kinetics and sintering mechanisms of hydro-thermally obtained hydroxyapatite," Materials Chemistry and Physics, vol. 111, no. 1, pp. 180$185,2008$. 

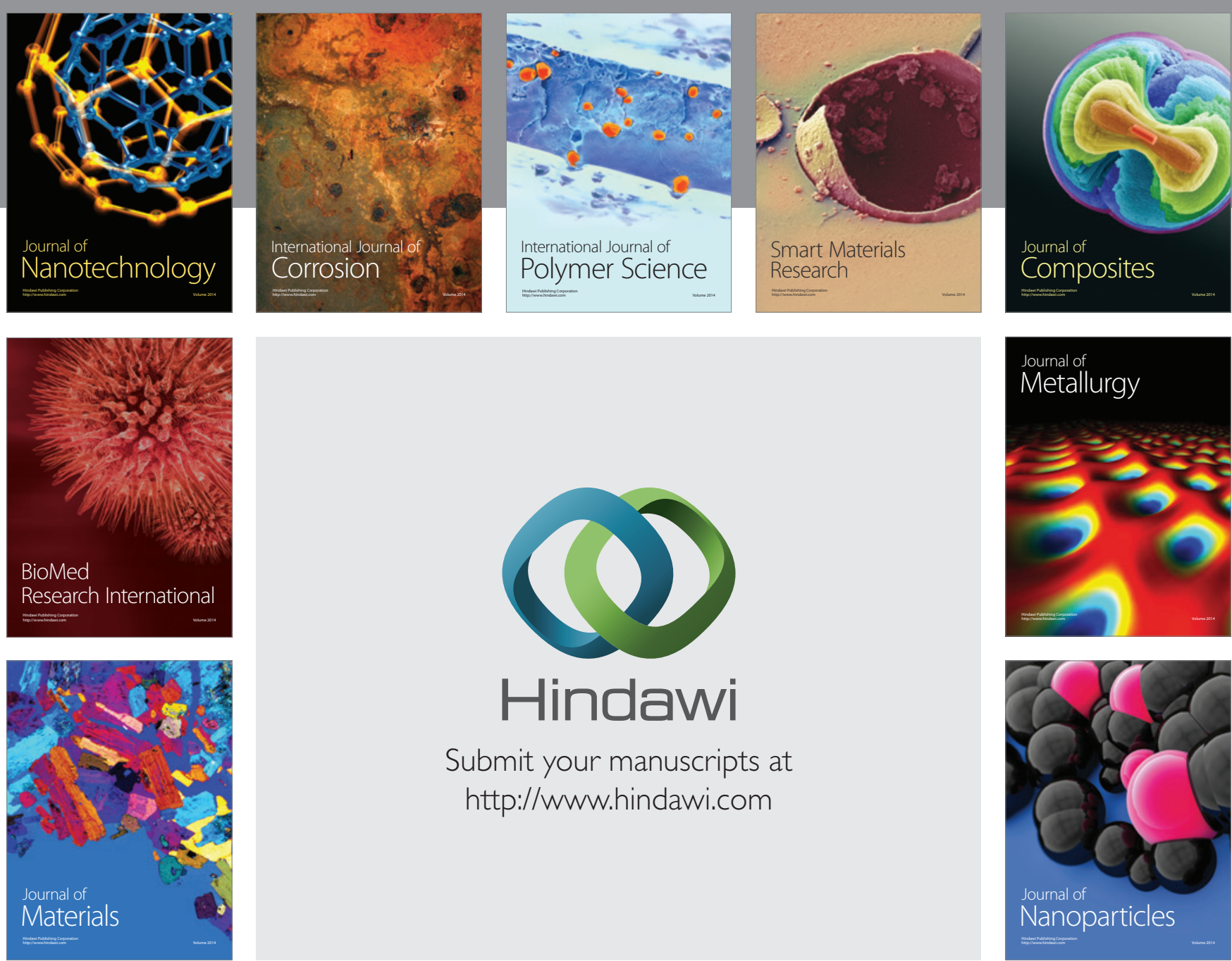

\section{Hindawi}

Submit your manuscripts at

http://www.hindawi.com

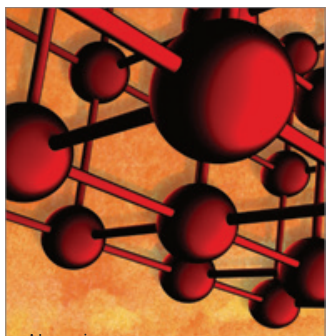

Materials Science and Engineering
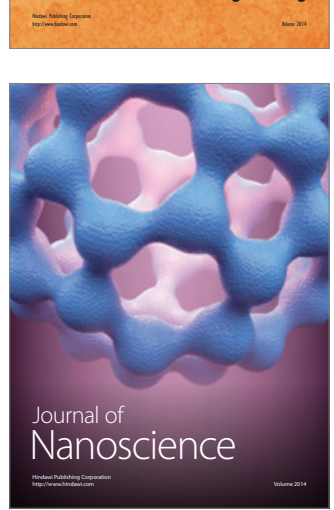
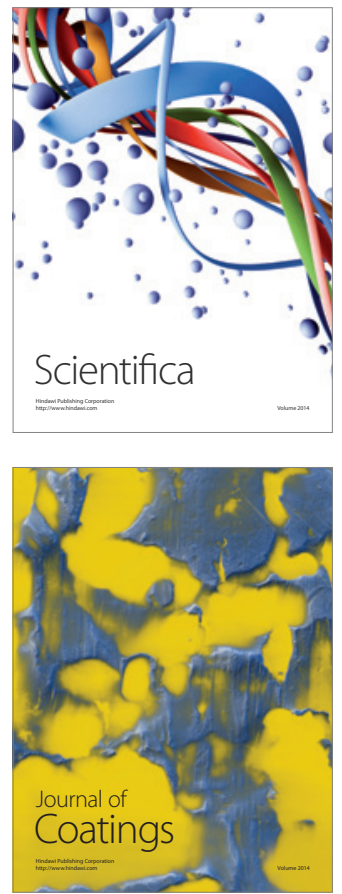
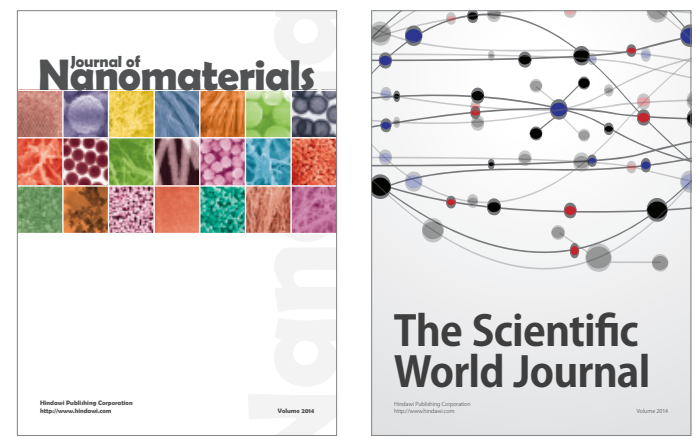

The Scientific World Journal
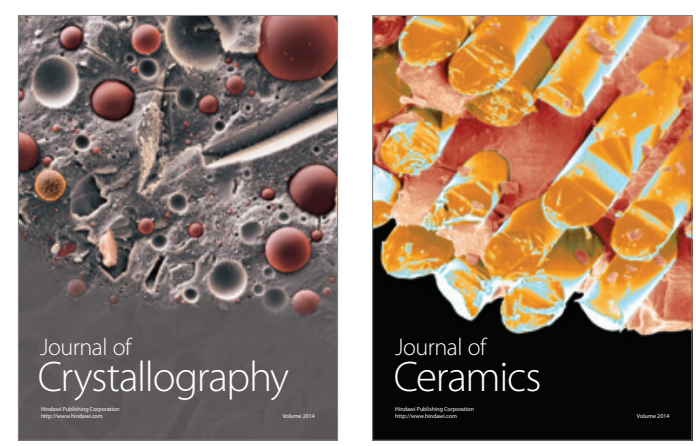
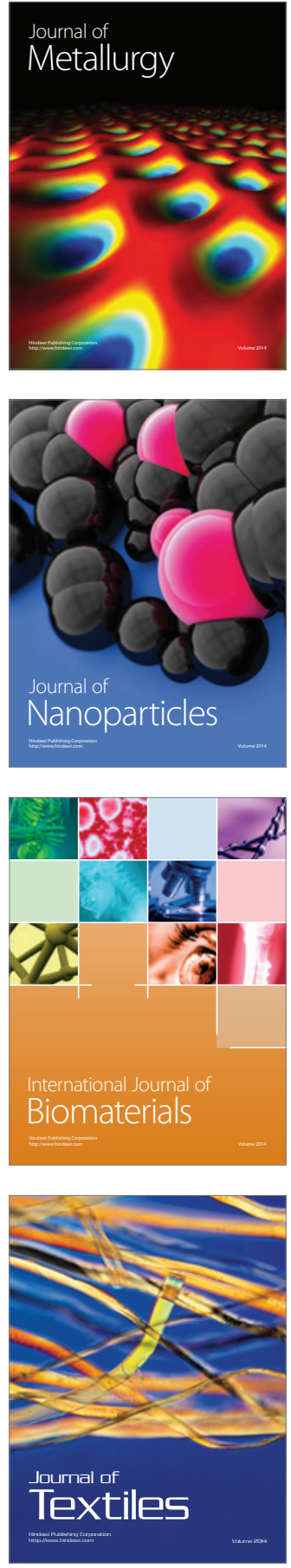